\title{
Tracheobronchial mucociliary clearance in asthma: impairment during remission
}

\author{
D PAVIA, JRM BATEMAN, NF SHEAHAN, JE AGNEW, SW CLARKE \\ From the Departments of Thoracic Medicine and Medical Physics, Royal Free Hospital and School of \\ Medicine, London
}

\begin{abstract}
Tracheobronchial mucociliary clearance was measured in eight non-smoking patients with asthma in complete remission. The patients were symptom free and required no medication whatsoever for one to six months before assessment. Mucociliary clearance was measured with an objective, radioaerosol technique. For comparison, mucociliary clearance of eight non-smoking, healthy subjects with physical characteristics and pulmonary function similar to those of the asthmatics was also measured on two occasions. In their first assessment the healthy subjects inhaled the tracer radioaerosol under experimental conditions similar to those used for the asthmatics; in the second assessment they inhaled the radioaerosol rapidly to simulate the asthmatic pattern of deposition. Under similar experimental conditions the radioaerosol was deposited more proximally in the asthmatic subjects than in the normal subjects and the difference was statistically significant $(p<0.01)$. When, however, the depth of radioaerosol lung penetration was similar in the two groups, there was evidence of a significantly $(p<0.01)$ poorer mucociliary clearance six hours after radioaerosol inhalation in the asthmatic than in the healthy group. These findings raise the question whether asthma ever remits completely.
\end{abstract}

Several studies have shown impaired mucus transport from the trachea,' the main bronchi, ${ }^{2}$ or the whole of the tracheobronchial tree ${ }^{3-4}$ in patients with stable asthma.

Mucociliary clearance is depressed after infection with, for example, influenza $\mathrm{A}^{\text {virus }}{ }^{5}$ or Mycoplasma pneumoniae $e^{6}$ and in these circumstances a period of months is required for complete recovery. Clearance is also depressed in symptom free smokers and, again, recovery occurs over some months.? In patients with chronic bronchitis, however, we have shown that stopping smoking for one year or more resulted in no improvement of clearance. ${ }^{8}$

In the present study we attempted to ascertain whether the depression of mucociliary clearance characteristic of asthmatic patients is reversed during remissions of the disease.

\section{Methods}

\section{TECHNIQUE}

The radioaerosol technique was used to measure

Address for reprint requests: Dr D Pavia, Department of Thoracic Medicine, Royal Free Hospital, London NW3 2QG.

Accepted 19 September 1984 lung mucociliary clearance in an objective, noninvasive manner." Five micron polystyrene particles labelled with the radionuclide technetium $99 \mathrm{~m}$ $\left({ }^{99} \mathrm{~m} \mathrm{Tc}\right)$, which has a half life of six hours, were generated by a spinning top generator ${ }^{10}$ located within an airtight tank. The volunteer subjects, wearing a noseclip, inhaled the radioaerosol from the tank via a mouthpiece. Eight discrete breaths, each 0.451 , of air carrying radioaerosol were taken by the subjects. Each breath began from roughly functional residual capacity. The volume of the breath was limited by a Krogh spirometer connected in series with the tank. The spirometer had a microswitch that could be preset to close the inspiratory solenoid valve after the required volume had been inhaled. The inspiratory flow rate was measured by a pneumotachygraph located between the spirometer and the tank and was recorded on an ultraviolet recorder. Each breath from the tank was followed by a three second breath holding pause to enable the radioaerosol to deposit by sedimentation at the furthest point of entry into the lung. After inhalation of the radioaerosol the patients rinsed their mouths and gargled with water three times to remove any radioaerosol deposited in the oropharynx and they drank some water to clear the oesophagus. 
The amount of radioaerosol initially deposited within the lungs and its subsequent clearance were monitored by two scintillation counters. The counters were located within lead collimators, and were placed anteriorly and posteriorly to the subject's chest. The wide angle field of view of the counters permitted the radioactivity present in most of both lungs to be seen but it excluded that present in the stomach." Counts over the chest were made at hourly intervals for six hours after inhalation of the radioaerosol and a final count was made at 24 hours. All counts were corrected for background radiation and physical decay of the radionuclide. All counts were expressed as percentages of the initial count (to overcome unavoidable differences in initial lung burden) to yield whole lung clearance curves. Subtracting the 24 hour whole lung retention-which was taken to be an estimate of alveolar deposition and therefore not available for mucus clearancefrom the other readings yielded tracheobronchial clearance curves.

None of the patients (or healthy controls) coughed during the six hour observation period.

Informed written consent was obtained from all the subjects before commencement of the tests. The initial lung burden per study amounted, on average, to about $30 \mu \mathrm{Ci}(1.1 \mathrm{MBq})$ of ${ }^{99 \mathrm{~m}} \mathrm{Tc}$, resulting in an absorbed radiation dose to the lungs of the order of 12 mrem ( $0.12 \mathrm{mSv}$.

The patients underwent measurement of their tracheobronchial mucociliary clearance on one occasion and the healthy subjects were studied twice. In the first assessment the healthy subjects inhaled the tracer radioaerosol under predominantly laminar flow conditions-that is, with an inspiratory flow rate of less than $301 \mathrm{~min}^{-1}$, similar to that achieved by the patients. In their second assessment they were instructed to inhale the tracer radioaerosol under conditions of more turbulent flow-that is, with an inspiratory flow rate about 601 $\min ^{-1}$.

Before each study forced vital capacity (FVC), forced expiratory volume in $1 \mathrm{~s}\left(\mathrm{FEV}_{1}\right)$, and maximum mid expiratory flow rate (MMFR $25-75$ ) were measured with a Vitalograph and the peak expiratory flow rate (PEFR) was measured with a Wright peak flow meter. The flow rates at $25 \%$ and $50 \%$ of vital capacity $\left(\dot{\mathrm{V}} \max _{25}\right.$ and $\left.\dot{\mathrm{V}} \max _{50}\right)$ were measured from maximal expiratory flow-volume (air) curves with an Ohio 840 spirometer connected to a Bryans $\mathrm{X}-\mathrm{Y}$ plotter. The highest value from three technically acceptable attempts was recorded for all pulmonary function indices measured.

The data were not normally distributed and statistical significance was assessed by the non-parametric Wilcoxon rank sum test for paired data. ${ }^{12}$
PATIENTS

Eight patients (four male and four female) with remission of their asthma were recruited from the outpatient asthma clinic of the Royal Free Hospital for study. These patients had taken no medication whatsoever for at least one month (range one to six months) before being investigated. All were nonsmokers. The mean (SEM) age, height, and weight for the group were: $31(3)$ years, $1.69(0.03) \mathrm{m}$ and 67 (4) $\mathrm{kg}$. The patients were compared with a healthy non-smoking control group comprising four men and four women with mean (SEM) age, height, and weight of $36(6)$ years, $1.71(0.05) \mathrm{m}$, and $72(4) \mathrm{kg}$ respectively. The two groups were thus similar in physical characteristics.

The table gives the mean (SEM) of the pulmonary function indices for the two groups. (There were no significant differences in the pulmonary function indices between the two runs for the healthy control group and the values quoted are means for the two runs.) There was no significant difference between the two groups for any of the indices of airway function.

\section{Results}

The mean (SEM) inspiratory flow rates during the radioaerosol inhalation at the first assessment were 25 (4) $1 \mathrm{~min}^{-1}$ and 23 (4) $1 \mathrm{~min}^{-1}$ for the asthmatics and healthy subjects. The mean alveolar depositions for the asthmatic and healthy control groups were $46 \%(4 \%)$ and $60 \%(3 \%)(\mathrm{p}<0.01)$. This indicated that on average the test radioaerosol was deposited more peripherally in the healthy control than in the asthmatic group and that $54 \%$ of the initial lung burden on average was available for clearance via the mucociliary escalator in the asthmatics compared with only $40 \%$ for the controls. Figure 1 shows the mean whole lung clearance and tracheobronchial clearance curves for the asthmatic

Pulmonary function indices (means with standard errors in parentheses) in asthmatic and control subjects*

\begin{tabular}{|c|c|c|}
\hline $\begin{array}{l}\text { Pulmonary function } \\
\text { index }\end{array}$ & $\begin{array}{l}\text { Asthmatics in } \\
\text { remission }\end{array}$ & $\begin{array}{l}\text { Healthy } \\
\text { controls }\end{array}$ \\
\hline $\begin{array}{l}\% \text { predicted } \mathrm{FEV}_{1} \dagger \\
\% \text { predicted PEFR }{ }^{\dagger} \\
\text { FEV } / \text { FVC }(\%) \dagger \\
\% \text { predicted MMFR }{ }_{25-75} \dagger \\
\% \text { predicted } \max _{50} \max ^{\dagger} \\
\% \text { predicted } \max _{25} \ddagger\end{array}$ & $\begin{array}{r}110(5) \\
98(5) \\
90(3) \\
99(6) \\
70(7) \\
59(7)\end{array}$ & $\begin{array}{r}109(7) \\
99(8) \\
87(3) \\
97(9) \\
74(5) \\
64(7)\end{array}$ \\
\hline
\end{tabular}

*None of the differences is significant at the $5 \%$ level (Wilcoxon rank sum test).

†Predicted values from Cotes. ${ }^{13}$

$\ddagger$ Predicted values from Knudson et al. ${ }^{14}$

PEFR-peak expiratory flow, rate; MMFR $_{25-75}$-maximum mid expiratory flow rate; $V \max _{50}, V_{\max _{25}}$ flow rates at $50 \%$ and $25 \%$ of vital capacity. 

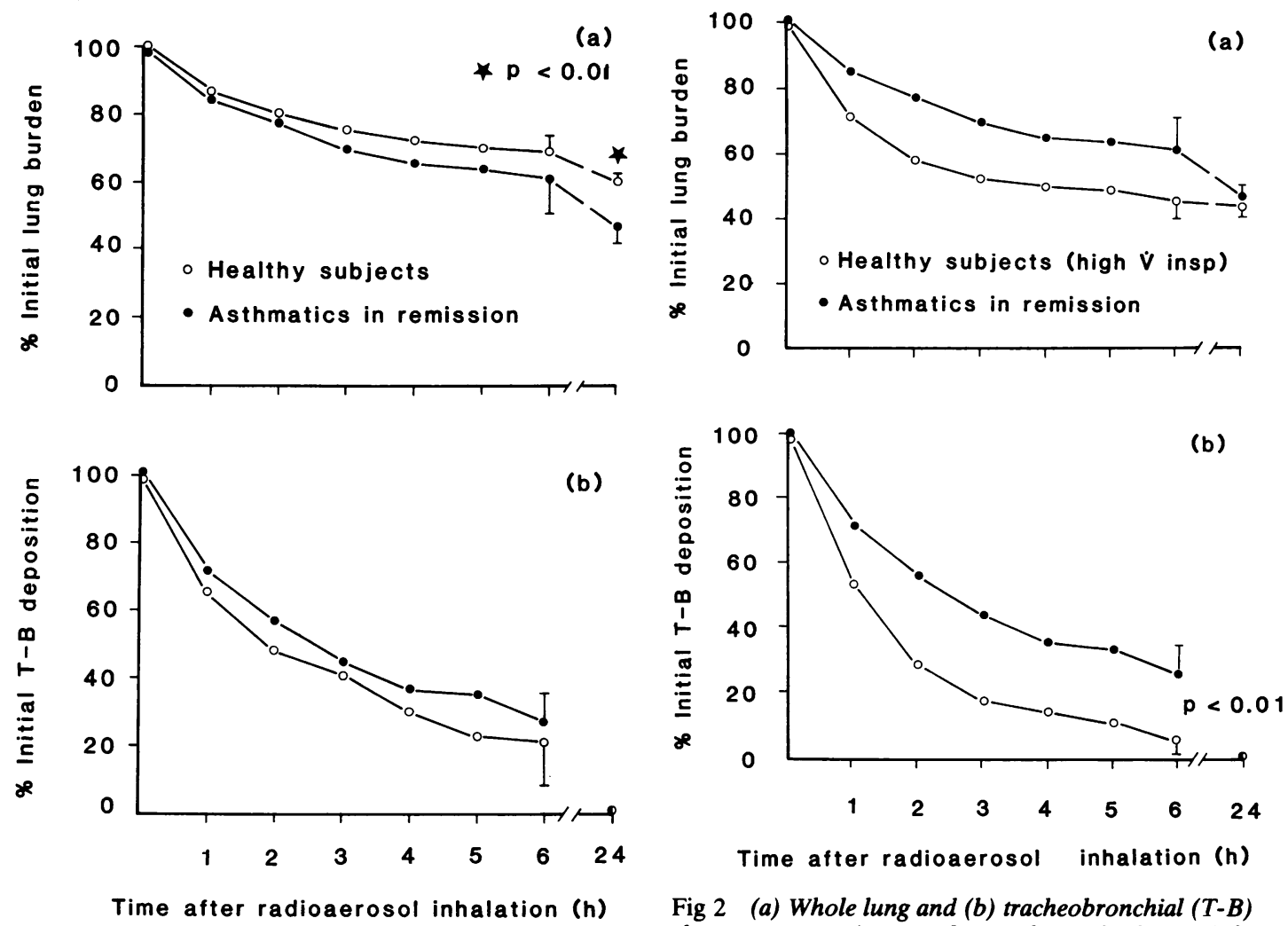

Fig 1 (a) Whole lung and (b) tracheobronchial (T-B) clearance curves (mean values with standard errors) for eight asthmatic subjects in remission and eight healthy subjects. Both groups inhaled the tracer radioaerosol under similar experimental conditions.

and control groups. There was no significant difference in the quantity of radioaerosol cleared at any one time between the two curves.

In the second study on the control group the mean (SEM) inspiratory flow rate during radioaerosol inhalation was $50(8) 1 \mathrm{~min}^{-1}$ - that is, about twice that of the asthmatic group $(p<0.01)$. This higher flow rate resulted in a mean alveolar deposition of $43 \%(6 \%)$, which was similar to the alveolar deposition in the asthmatic group-that is, $46 \%$ (4\%). Figure 2 shows the mean whole lung clearance and tracheobronchial curves for the asthmatic and control (second assessment) groups. In this comparison the clearance curves for the healthy group were on average faster than those of the asthmatics, although significance was only achieved for the comparison between the two tracheobronchial clearance curves at six hours $(\mathrm{p}<0.01)$.

Fig 2 (a) Whole lung and (b) tracheobronchial (T-B) clearance curves (mean values with standard errors) for eight asthmatic subjects in remission and eight healthy subjects. To achieve similar alveolar deposition the healthy subjects here had inhaled radioaerosol at about twice the rate of the asthmatics.

\section{Discussion}

Deposition of inhaled radioaerosol in the human lung depends on, firstly, the physical properties of the aerosol; secondly, the mode of inhalation; and thirdly, the patency of the airways. ${ }^{15}$ In this study when the asthmatic patients inhaled the radioaerosol with inspiratory flows similar to those of the healthy subjects a significant reduction in alveolar deposition was noted. Since the physical properties of the aerosol and the mode of inhalation were strictly controlled within and between the two groups we may reasonably assume that the difference in alveolar deposition might have arisen from changes in patency of the airways in the asthmatic group. The indices of forced ventilation for the asthmatic patients were, however, virtually identical to those of the healthy group. It is tempting to infer from these results that the "orthodox" pulmonary function tests performed in this study were not ade- 
quately sensitive in detecting changes in airway patency. ${ }^{16}$ The cardinal difference between airway patency inferred from the topographical distribution of the aerosol and that based on measurements of pulmonary function tests is that radioaerosol deposition took place during quiet inspiration, whereas the pulmonary function tests required forceful expiratory manoeuvres.

An additional possible explanation of the proximal deposition of the radioaerosol in the asthmatic subjects is asynchronous ventilation in various lung zones, giving rise to premature deposition by impaction. ${ }^{17}$

When the healthy subjects were instructed to inhale the test radioaerosol more quickly, their alveolar deposition was reduced and was now similar to that of the asthmatics. The reduction in alveolar deposition was due to increased impaction, resulting directly from the higher linear airflow velocities in the lung and presumably augmented by turbulence. We propose that in asthma in remission there must exist alterations in the architecture of the airways - possibly due to one or more of the following factors: (1) the presence of increased mucus; (2) airway narrowing due to oedema or spasm, or both; (3) increased tortuosity in the airways; (4) asynchronous ventilation between lung zones (arising possibly from localised variations in lung compliance). The fact that the normal subjects needed to double their inhalation flow rate to lower the alveolar deposition to asthmatic levels argues that quite large airway alterations persist when asthmatic subjects are seemingly in remission.

Lung mucociliary clearance has been shown to be impaired in patients with mild, stable asthma. ${ }^{34} \mathrm{Sev}$ eral factors may play a part, including alteration in the amount or physicochemical properties (or both) of lung secretions, changes in the integrity of the ciliated epithelium, and the presence of a ciliary beat inhibiting factor in the lung secretions of asthmatics. ${ }^{18}$

Under conditions of similar inspiratory flow the control subjects showed slightly, but not significantly, faster tracheobronchial clearance than the asthmatics (fig $1 b$ ); but this occurred despite deeper penetration of the radioaerosol (significantly higher alveolar deposition), and the resulting longer mean path length for radioaerosol clearance from the site of deposition to the trachea. When the alveolar deposition for the two groups-and hence (approximately) the mean clearance path lengthwas equalised by the high flow rate manoeuvres in the control subjects, ${ }^{19}$ it became apparent that tracheobronchial clearance was appreciably faster in controls than in asthmatic subjects (fig $2 b$ ). The difference in the amount of radioaerosol cleared at any one time between the low and high flow rates is most apparent over the first two to three hours of the test. This represents the rapid removal of proximally deposited aerosol particles with high inspiratory flow rates and is in agreement with previously reported data. ${ }^{20}$ Although it cannot be confidently gauged from the present data, it may well be that asthmatics in remission have difficulties in clearing mucus from proximal airways. Their reduced alveolar deposition implies a considerable deposition of particles proximally. Yet over the first hour of the test they were able to clear only about $28 \%$ of tracheobronchial deposition as compared with about $47 \%$ in the (high flow) normals with proximal deposition.

Pharmacological agents such as methylxanthines, corticosteroids, sympathomimetic bronchodilators, and sodium cromoglycate have been shown to have a stimulatory effect on lung mucociliary clearance in addition to their bronchodilating, anti-inflammatory, and prophylactic properties. ${ }^{1921}$ The findings of this study of apparent alteration in the architecture of the airways of asthmatics, together with evidence of impaired clearance despite the fact that these patients were in apparent remission, raise doubt about whether asthma does ever truly remit. If it does not, the question naturally arises of whether medication should be maintained, albeit at a low level, during periods of apparent remission.

\section{References}

1 Mezey RJ, Cohn MA, Fernandez RJ, Januszkiewicz AJ, Wanner A. Mucociliary transport in allergic patients with antigen-induced bronchospasm. Am Rev Respir Dis 1978;118:677-84.

2 Foster WM, Langenback EG, Bergofsky EH. Lung mucociliary function in man: interdependence of bronchial and tracheal mucus transport velocities with lung clearance in bronchial asthma and healthy subjects. Ann Occup Hyg 1982;26:227-44.

3 Bateman JRM, Pavia D, Sheahan NF, Agnew JE, Clarke SW. Impaired tracheobronchial clearance in patients with mild stable asthma. Thorax 1983;38:463-7.

4 Agnew JE, Bateman JRM, Pavia D, Clarke SW. A model for assessing bronchial mucus transport. J Nucl Med 1984;25:170-6.

5 Camner P, Jarstrand C, Philipson K. Tracheobronchial clearance in patients with influenza. Am Rev Respir Dis 1973;108:131-5.

6 Jarstrand C, Camner P, Philipson K. Mycoplasma pneumoniae and tracheobronchial clearance. Am Rev Respir Dis 1974;110:415-9.

7 Camner P, Philipson K, Arvidsson T. Withdrawal of cigarette smoking. A study of tracheobronchial clearance. Arch Environ Health 1973;26:90-2.

8 Agnew JE, Little F, Pavia D, Clarke SW. Mucus clearance from the airways in chronic bronchitis - smokers 
and ex-smokers. Bull Eur Physiopath Respir 1982; 18:473-84.

9 Pavia D, Sutton PP, Agnew JE, Lopez-Vidriero MT, Newman SP, Clarke SW. Measurement of bronchial mucociliary clearance. Eur J Respir Dis 1983;64, suppl 127:41-56.

10 May KR. An improved spinning top homogeneous spray apparatus. J Appl Phys 1949;20:932-8.

11 Thomson ML, Pavia D. Long-term tobacco smoking and mucociliary clearance from the human lung in health and respiratory impairment. Arch Environ Health 1973;26:86-9.

12 Siegel S. Non-parametric statistics. New York: McGraw Hill, 1956.

13 Cotes JE. Lung function: principles and application in medicine. 3rd edition. Oxford: Blackwell, 1975.

14 Knudson RJ, Slatin RC, Lebowitz MD, Burrows B. The maximal expiratory flow-volume curve. Normal standards, variability, and effects of age. Am Rev Respir Dis 1976;113:587-600.

15 Pavia D, Thomson ML, Clarke SW, Shannon HS. Effect of lung function and mode of inhalation on penetration of aerosol into the human lung. Thorax
1977;32:194-7.

16 Agnew JE, Pavia D, Clarke SW. Airways penetration of inhaled radioaerosol: an index of small airways function? Eur J Respir Dis 1981;62:239-55.

17 Agnew JE. Aerosol contributions to the investigation of lung structure and ventilatory function. In: Clarke SW, Pavia D, eds. Aerosols and the lung: clinical and experimental aspects. London: Butterworth, 1984:92126.

18 Dulfano MJ, Luk CK. Sputum and ciliary inhibition in asthma. Thorax 1982;37:646-51.

19 Pavia D. Lung mucociliary clearance. In: Clarke SW, Pavia D, eds. Aerosols and the lung: clinical and experimental aspects. London: Butterworth, 1984:127-55.

20 Agnew JE, Bateman JRM, Watts M, Paramananda V, Pavia D, Clarke SW. The importance of aerosol penetration for lung mucociliary clearance studies. Chest 1981;80, suppl:843-6.

21 Pavia D, Sutton PP, Lopez-Vidriero MT, Agnew JE, Clarke SW. Drug effects on mucociliary function. Eur J Respir Dis 1983;64, suppl 128:304-17. 